\title{
DIVERSIDADE GENÉTICA EM COLEÇÕES AMAZÔNICAS DE GERMOPLASMA DE CUPUAÇUZEIRO [Theobroma grandiflorum (Willd. ex Spreng.) Schum.] ${ }^{1}$
}

\author{
RAFAEL MOYSÉS ALVES², CARLOS ROGÉRIO DE SOUSA SILVA', \\ MARIA SUELLEM DA CONCEIÇÃO SILVA ${ }_{2}{ }_{2}$ DARLY CAROLINE DE SOUZA SILVA ${ }^{5}$ \\ ALEXANDRE MAGNO SEBBENN ${ }^{6}$
}

RESUMO- Este trabalho teve por finalidade avaliar a diversidade genética e o parentesco de 24 acessos de Theobroma grandiflorum, introduzidos de três unidades da Embrapa, objetivando sua utilização como genitores no programa de hibridação da espécie. Os marcadores genéticos utilizados foram lócus heterólogos de microssatélites desenvolvidos para cacaueiro. Foram encontrados 45 alelos na população estudada. $\mathrm{O}$ número médio efetivo de alelos por lócus $(2,33)$ foi menor do que o número médio de alelos por lócus $(3,21)$, indicando que muitos alelos têm baixa frequência. A heterozigosidade observada nos lócus polimórficos variou de 0,33 a 1,00 com média de 0,54 e a heterozigosidade esperada variou entre 0,48 a 0,76 com média de 0,54 . $\mathrm{O}$ índice de fixação médio entre lócus $(0,003)$ não foi significativamente diferente de zero. A estimativa do parentesco entre pares de indivíduos indica que alguns podem ser parentes, entre meios-irmãos e clones. Os resultados sugerem que os acessos de Theobroma grandiflorum analisados contêm um moderado nível de diversidade genética e ausência de endogamia e, portanto, grande potencial para utilização em programas de melhoramento genético.

Termos para indexação: Microssatélite, endogamia, diversidade genética.

\section{GENETIC DIVERSITY IN BRASILIAN AMAZON COLLECTIONS OF CUPUASSU TREE GERMPLASM [Theobroma grandiflorum (Willd. ex Spreng.) Schum]}

\begin{abstract}
This study aimed to evaluate the genetic diversity and relatedness of 24 accessions of Theobroma grandiflorum, originating from three units of Embrapa, aiming their use as parents in hybridization specie programs. The genetic markers used were heterologous microsatellite loci developed for cocoa. In the population studied 45 alleles were found. The effective average number of alleles per locus (2.33) was less than the average number of alleles per locus (3.21), indicating that many alleles have low frequency. The observed heterozygosity at polymorphic loci ranged from 0.33 to 1.00 with a mean of 0.54 and expected heterozygosity ranged from 0.48 to 0.76 with a mean of 0.54 . The fixation index medium between loci $(0.003)$ was not significantly different from zero. The estimate of relatedness between pairs of individuals indicates that some may be relatives, including half-brothers and clones. The results suggest that the accesses of $T$. grandiflorum analyzed contain a moderate level of genetic diversity and absence of inbreeding and therefore great potential for use in breeding programs.
\end{abstract}

Index terms: Microsatellite, inbreeding, genetic diversity.

\footnotetext{
${ }^{1}$ (Trabalho 118-13). Recebido em: 14-03-2013. Aceito para publicação em: 19-07-2013. Suporte financeiro: Embrapa Amazônia Oriental e Ceplac.

${ }^{2}$ Pesquisador, Embrapa Amazônia Oriental, CP 48, Belém-PA. E mail: rafael-moyses.alves@embrapa.br;

${ }^{3}$ Pesquisador (DCR), ERJOH, CEPLAC, BR 316 km 17, CP 46, Marituba-PA, E mail: carlos-roger@hotmail.com

${ }^{4}$ Mestranda em Agronomia, Universidade Estadual Paulista, CP 56, Ilha Solteira-SP. E-mail: suellem_ufra@yahoo.com.br

${ }^{5}$ Agrônoma, Universidade Federal Rural da Amazônia (UFRA). E-mail: darlycaroline@bol.com.br

${ }^{6}$ Pesquisador, Instituto Florestal de São Paulo. E mail: alexandresebbenn@yahoo.com.br
} 


\section{INTRODUÇÃO}

A importância do gênero Theobroma L., família Malvaceae (ALVERSON et al., 1999), deve-se, principalmente, à relevância econômica do cacaueiro (Theobroma cacao L.) e, em menor monta, à emergente procura pelo cupuaçuzeiro [Theobroma grandiflorum (Willd. ex Spreng.) Schum.], únicas espécies do gênero cultivadas comercialmente (SILVA et al., 2011).

O cupuaçuzeiro é considerado uma das culturas mais rentáveis da região Amazônica, sendo muito apropriada a sistemas agroflorestais, consorciando-se favoravelmente com várias culturas. A procura por cupuaçu vem aumentando sua importância econômica em todos os estados da federação, e começa a atrair a atenção mundial do mercado de frutas exóticas tropicais (SOUZA et al., 2002).

A distribuição geográfica do cupuaçuzeiro originalmente restringia-se às áreas de floresta nativa ao sul do Rio Amazonas, oeste do Rio Tapajós, incluindo o sul e sudeste do Estado do Pará e a região "pré-amazônica" do Estado do Maranhão. Esta região foi considerada por Cuatrecasas (1964) como o centro de origem da espécie. Como o melhoramento genético do cupuaçuzeiro preconiza que a base genética utilizada seja a mais ampla possível, há necessidade de prospectar as populações remanescentes dessa região, pois é esperado que ela concentre a máxima variabilidade da espécie (ALVES et al., 2007).

$\mathrm{O}$ avanço da fronteira agrícola na região Norte do Brasil, especialmente no Estado do Pará, coloca em risco áreas consideráveis de ocorrência de populações naturais de cupuaçuzeiro. A Amazônia brasileira, além de ser o centro de máxima diversidade, constitui-se a única reserva de variabilidade genética da espécie. Porém, além de o melhoramento genético da espécie ser ainda incipiente, é restrita a disponibilidade de germoplasma para ser utilizado pelos melhoristas. Além do mais, as populações nativas remanescentes, que poderão servir como fontes de genes e genótipos, estão sofrendo forte erosão genética pela ação antrópica, por localizarem-se na área denominada "Arco do fogo" (sul e sudeste do Pará), área esta muito ameaçada pelo desmatamento, em função da exploração ilegal de madeira e da expansão da atividade agropecuária.

A demanda por materiais melhorados estimulou a criação de programas de melhoramento genético com a espécie na Embrapa Amazônia Oriental (CPATU) e Embrapa Amazônia Ocidental
(CPAA) e o estabelecimento de coleções ex situ (Banco Ativo de Germoplasma - BAG), para a conservação da variabilidade genética e seleção preliminar de materiais promissores e resistentes a patógenos.

Foram estabelecidas coleções de cupuaçuzeiro na Embrapa Rondônia (CPAFRO), Embrapa Amazônia Ocidental (CPAA) e Embrapa Amazônia Oriental (CPATU. Baseados em uma criteriosa caracterização e avaliação, foram selecionados os acessos mais promissores em cada Unidade, que apresentavam boas características de produção de frutos e resistência à Moniliophthora perniciosa, agente etiológico da doença vassoura-de-bruxa. Esses genótipos foram enviados para as três unidades da Embrapa para estudos de campo e serviram de base para a formação da coleção empregada neste estudo. Estes acessos foram integralizados à coleção amazônica de germoplasma de espécies de Theobroma L. "George O'Neill Addison", pertencente à Embrapa - CPATU, em Belém, Estado do Pará, Brasil (SILVA et al., 2004).

A caracterização da diversidade genética e do parentesco dentro e entre as coleções é fundamental para a correta recombinação e seleção da variabilidade genética do material conservado (ALVES et al., 2007). Dentre as diferentes formas de caracterizar a divergência, os marcadores microssatélites são especialmente úteis para caracterizar a diversidade genética e o parentesco em espécies arbóreas, devido ao alto polimorfismo em termos do número de alelos por lócus.

A utilização de primers microssatélites heterólogos é uma abordagem útil na avaliação de espécies geneticamente próximas (LEMES et al., 2007). A chance de sucesso nessa transferência é inversamente proporcional a distância evolucionária entre as espécies. No caso do gênero Theobroma, foram isolados, sequenciados e avaliados pelo Centre de Coopération Internationale en Recherche Agronomique pour le Développement (CIRAD), France, e USDA-ARS Subtropical Horticulture Research Station, Miami, aproximadamente 320 lócus microssatélites em $T$. cacao (LANAUD et al., 1999; PUGH et al., 2004; SCHNELL, 2007). Primers desenhados para T. cacao foram usados para amplificar microssatélites de outras espécies do gênero, como T. grandiflorum (LANAUD et al., 1999; ALVES et al., 2007). Em T. cacao, marcadores microssatélites têm sido utilizados para entender a origem e domesticação da espécie (LANAUD et al., 1999), elaboração de mapas genéticos (RISTERUCCI et al., 2000; PUGH et al., 2004), estudos de diversidade genética (SERENO et al., 2006) e caracterização de germoplasma (IRISH, 
2010)

Dentro deste contexto, os objetivos deste trabalho foram avaliar a diversidade genética, a endogamia e o parentesco de 24 acessos de $T$. grandiflorum originados de diferentes coleções, gerenciadas pela Empresa Brasileira de Pesquisa Agropecuária (EMBRAPA), utilizando marcadores microssatélites.

\section{MATERIAL E MÉTODOS}

Avaliou-se, por meio de marcadores moleculares, a diversidade genética de 24 acessos de cupuaçuzeiro (Tabela 1) oriundos da Embrapa CPAFRO, coordenadas geográficas de $08^{\circ} 47^{\prime} 42^{\prime \prime}$ $\mathrm{S}$ e $63^{\circ} 50^{\prime} 45^{\prime}$ 'W, município de Porto Velho - RO; Embrapa - CPAA, $3^{\circ} 8^{\prime} \mathrm{S}$ e $59^{\circ} 52^{\prime} \mathrm{W}$, município de Manaus - AM e Embrapa - CPATU, localizada entre as coordenadas de $01^{\circ} 24^{\prime} 59^{\prime \prime} \mathrm{S}$ e $48^{\circ} 20^{\prime} 55^{\prime \prime} \mathrm{W}$, no município de Belém - PA.

Tecidos foliares dos acessos selecionados foram enviados ao Laboratório de Biologia Molecular da CEPLAC, localizado em Marituba, Pará, onde foram realizadas as extrações dos DNAs com base no protocolo de Doyle e Doyle (1990), já utilizado por Alves et al. (2007).

Utilizaram-se 14 primers heterólogos de microssatélites desenvolvidos para Theobroma cacao (LANAUD et al., 1999; PUGH et al., 2004), , baseado na seleção realizada por Alves et al. (2007). As reações foram preparadas com volume final de $13 \mu$, contendo 15 ng de DNA genômico; $100 \mu \mathrm{M}$ de cada dNTPs; $0,2 \mu \mathrm{M}$ de cada primer (forward e reverse); tampão da enzima ( $50 \mathrm{mM} \mathrm{KCl} ; 10 \mathrm{mM}$ Tris- $\mathrm{HCl} \mathrm{pH}$ 8,$8 ; 0,1 \%$ Triton $\mathrm{X}-100 ; 1,5 \mathrm{mM} \mathrm{MgCl}$ ) e 1 unidade de Taq DNA polimerase.

As reações de PCR foram amplificadas em termociclador GeneAmp PCR System 9700 (Applied Biosystems, Foster City, EUA), programado inicialmente com um ciclo de desnaturação a $94^{\circ} \mathrm{C}$, por $4 \mathrm{~min}$; seguido de 10 ciclos de $94^{\circ} \mathrm{C}$, por 40 $\mathrm{s}$, touch down, decrescendo $1^{\circ} \mathrm{C}$ por ciclo, com temperatura de anelamento inicial de $59^{\circ} \mathrm{C}$ e final de $49^{\circ} \mathrm{C}$, por $40 \mathrm{~s}, \mathrm{e} 72^{\circ} \mathrm{C}$, por $60 \mathrm{~s}$; seguido de 30 ciclos de $94^{\circ} \mathrm{C}$, por $30 \mathrm{~s}, 46^{\circ} \mathrm{C}$ ou $51^{\circ} \mathrm{C}$, por $60 \mathrm{~s}$, e $72^{\circ} \mathrm{C}$, por $60 \mathrm{~s}$. As corridas de eletroforese foram realizadas em cubas verticais de sequenciamento S2001 (Life Technologies, California, USA).

Após aplicação de $4 \mu \mathrm{L}$ das reações nos géis, as amostras foram submetidas a uma corrida eletroforética inicial de 10 minutos a $40 \mathrm{~W}$. Após este procedimento, a potência elétrica era elevada para 60 $\mathrm{W}$, por 3 horas. Os fragmentos foram separados em géis desnaturantes de poliacrilamida a $6 \%$ e $7 \mathrm{M}$ de ureia. A revelação do gel foi realizada com nitrato de prata, conforme Creste et al. (2001).

A genotipagem em cada lócus foi obtida pela leitura direta das bandas no gel, onde a diversidade genética foi caracterizada pelo número total de alelos (A), número efetivo de alelos por lócus $\left(A_{e}\right)$, heterozigosidade observada $\left(H_{o}\right)$ e esperada $\left(H_{e}\right)$ em Equilíbrio Genético de Hardy-Weinberg e conteúdo de informação polimórfica (PIC). A inferência da endogamia dos genótipos foi estimada utilizando o índice de fixação e a significância estatística dos valores estimada por permutação (1.000). Os índices de diversidade genética, o índice de fixação e as permutações foram estimados com auxílio do programa FSTAT (GOUDET, 1995).

A utilidade do conjunto de primers avaliados, na discriminação de genótipos do banco, foi acessada com base em sua probabilidade combinada de inclusão e poder combinado de discriminação. As probabilidades de identidade $[P I]$ (PAETKAU et al. 1995) e de exclusão ( $P E)$ foram calculadas utilizando o programa IDENTITY, versão 1.0 (WAGNER; SEFC, 1999).

O parentesco entre os pares de acessos foi estimado utilizando o coeficiente de coancestria de J. Nanson, como descrito em Loisselle et al. (1995) e o programa SPagedi (HARDY; VEKEMANS, 2002). O coeficiente de coancestria entre pares de indivíduos corresponde ao coeficiente de endogamia nos descendentes deste cruzamento. Devido a erros nas estimativas de parentescos, originados da variação entre lócus, neste trabalho, apenas considerou-se relevantes estimativas de coancestrias $\geq 0,1$. Valores menores foram considerados como coancestrias igual a zero.

As análises de distância genética e de agrupamento entre os acessos de $T$. grandiflorum foram realizadas utilizando o programa POPTREE2 (TAKEZAKI et al., 2010). Utilizou-se a distância genética $D_{A}$ proposta por Nei et al.(1983). Realizouse a análise de agrupamento utilizando o método UPGMA (unweighted pair-group method with arithmetic mean), e a consistência dos agrupamentos foi verificada através da metodologia de bootstrap, utilizando 10.000 replicações (FELSENSTEIN, 1985).

O tamanho efetivo que estes 24 acessos $(n)$ representam em termos de coancestria $(\Theta)$ e endogamia $(F)$, foi estimado utilizando o método de Cockerham (1969).

$$
N_{\varepsilon}=\frac{0,5}{\Theta\left(\frac{n-1}{n}\right)+\frac{1+F}{2 n}}
$$




\section{RESULTADOS E DISCUSSÃO}

Foi obtido um banco de dados contendo a genotipagem molecular (DNA fingerprint) de 24 acessos do BAG de cupuaçuzeiro da EMBRAPA, utilizando os 14 marcadores moleculares microssatélites. Estes dados serão úteis na disponibilização das informações relativas ao acervo genético dos diferentes acessos de $T$. grandiflorum, presentes no BAG, minimizando o risco de perdas do patrimônio genético nacional de cupuaçuzeiro devido à erosão genética, e no registro e proteção de futuras cultivares lançadas pela EMBRAPA. Para essa genotipagem, foram selecionados 14 primers microssatélites, dos quais, 13 foram polimórficos e um monomórfico (Tabela 2), encontrados 45 alelos na população de estudo, sendo que, o número de alelos por lócus variou de um (mTcCIR54) a sete alelos (mTcCIR25), com média de 3,21 alelos por lócus. Os primers mais polimórficos foram o mTcCIR $25 \mathrm{e}$ o mTcCIR26, que amplificaram sete e cinco alelos, respectivamente, enquanto os primers $\mathrm{mTcCIR} 32$, mTcCIR58 e mTcCIR264 (todos com dois alelos), e o mTcCIR54 (monomórfico) apresentaram baixo polimorfismo. O número de alelos detectados é uma função do tamanho da amostra. Contudo, o resultado do presente estudo pode ser comparado com o do trabalho de Lanaud et al. (1999), com T. cacao, também utilizaram o mesmo número de genótipos na análise, obtendo média de 5,6 alelos por lócus, o que indica maior diversidade alélica do que a detectada em T. grandiflorum.

Regra geral, o número efetivo de alelos por lócus (Ae) foi inferior ao número de alelos nos lócus (A), variando de 1,00 (mTcCIR 54) a 3,99 (mTcCIR 25), com média de 2,33 alelos por lócus. Isto demonstra que muitos alelos têm baixa frequência ou são raros (Tabela 3). A heterozigosidade observada nos lócus polimórficos variou de 0,333 (mTcCIR 57) a 1,000 (mTcCIR 32 e mTcCIR 264) com média de 0,540. A heterozigosidade esperada para os lócus polimórficos variou entre 0,488 (mTcCIR 58) e 0,765 (mTcCIR 25), com média de 0,542. O índice de fixação (F) variou entre os lócus polimórficos de negativo a positivo (Tabela 3). Em três lócus, o índice de fixação foi negativo (variando de $-1,000$ a $-0,173$ ), sugerindo excesso de heterozigotos em relação ao esperado em equilíbrio de HardyWeinberg. Nos demais lócus polimórficos, os valores foram positivos (variando entre 0,063 e 0,440 ). A média entre lócus foi positiva $(0,003)$, mas baixa e não significativamente diferente de zero, o que sugere ausência de endogamia. Os resultados gerais, em termos de número de alelos, heterozigosidade e índice de fixação sugerem que os acessos de T. grandiflorum analisados apresentam um nível de diversidade genética moderado e ausência de endogamia.

Os acessos das três unidades de introdução amostradas apresentaram alelos exclusivos (Tabela 4). O germoplasma da Embrapa CPAFRO foi o que apresentou o maior número de alelos exclusivos (dois alelos; acessos 78RO e 79RO), seguido do representante do CPATU (um alelo; acesso 174AM) e do CPAA (um alelo; acesso 65AM). A presença de acessos contendo alelos exclusivos nos BAGs das três unidades de introdução de materiais é um indicativo de diversidade genética a ser explorada em suas áreas de prospecção.

Os lócus analisados apresentaram conteúdo de informação polimórfica (PIC), variando de zero (lócus mTcCIR54) a 71,2\% (lócus mTcCIR25), com valor médio de 43,9\% (Tabela 3). Excluindo-se o lócus monomórfico (mTcCIR 54), a média do valor de PIC sobe para 47,3\%. O baixo valor médio de PIC nos lócus de T. grandiflorum quando comparado aos valores encontrados em cacaueiro, deve-se, provavelmente, ao restrito número de acessos analisados e ao fato de tratar-se de lócus heterólogos. Os valores de PIC refletem o poder de discriminação dos lócus microssatélites analisados.

A probabilidade de identidade ou poder de inclusão (PI) corresponde à probabilidade de encontrar dois indivíduos com o mesmo genótipo para um determinado lócus na população. O lócus mTcCIR 264 apresentou a maior probabilidade de identidade (59,5\%), enquanto o lócus mTcCIR 25 apresentou a menor PI (10\%) (Tabela 3). O poder de inclusão combinado dos 14 lócus analisados, isto é, a probabilidade de encontrar dois perfis de DNA idênticos na população, utilizando este conjunto de primers, foi $3,551859 \times 10^{-8}$. O poder de discriminação (PE) combinado dos 14 lócus analisados, isto é, a probabilidade de excluir um não parente de uma paternidade ou maternidade foi 98,97\% (Tabela 3), o que demonstra a utilidade deste conjunto de primers na discriminação e controle de pedigree de genótipos de cupuaçuzeiro.

No dendrograma gerado a partir da distância genética $\mathrm{D}_{\mathrm{A}}$ (NEI et al., 1983) [Figura 1], destacase o agrupamento formado pelos acessos 215AM de Manacapuru e 84AM de Caapiranga, ambos do Amazonas, agrupamento este suportado por $74 \%$ dos bootstraps, portanto indicando forte proximidade genética entre eles. Em virtude de as áreas de coletas serem próximas, é possível que exista fluxo gênico intenso entre os dois locais, indicando um possível parentesco entre os acessos, portanto futuras 
hibridações envolvendo estes parentais deverão ser evitadas, pois poderá desencadear depressão por endogamia. Silva et al. (2011) reportam uma correlação negativa entre a proximidade genética dos parentais e a capacidade de produção de frutos. A relação entre esses materiais é mais forte que entre o acesso 215 AM e o $95 \mathrm{AM}$, seu descendente direto (suportado por $42 \%$ dos bootstraps).

Dois outros clusters que chamam a atenção estão relacionados ao acesso $186 \mathrm{AM}$, coletado no município de Codajás (AM), e seus descendentes, formados pelos acessos 42 AM PA, 46 AM, 93 AM e 94 AM. Destes, a mais forte relação foi a estabelecida entre o 186 AM e o 42 AM-PA (72\% de bootstrap). Portanto, retrocruzamentos com esse parental devem ser evitados. Os acessos 93AM e 94AM também guardam boa proximidade genética (44\% de bootstrap) devido à ancestralidade comum.

Os acessos coletados em Rondônia (RO), apesar dos baixos valores de bootstrap, tenderam a agrupar-se. Os materiais provenientes de Machadinho d'Oeste, $79 \mathrm{RO}$ e $80 \mathrm{RO}$, foram os mais próximos (bootstrap 22\%), seguidos pelos acessos coletados em Guajará-Mirim (77 RO) e Cacoal (78 RO) [bootstrap 10\%]. Isto indica certo grau de divergência entre esses acessos, possivelmente compartilham alelos entre si, porém não identicos por descendência. Devido à moderada distância genética, estes materiais poderiam ser hibridizados em programas de melhoramento de cupuaçuzeiro adaptados às condições de plantio no Estado de Rondônia.

Os acessos coletados em dois plantios comerciais do município de Tomé-Açu, Estado do Pará (85 PA e $88 \mathrm{PA})$ demonstraram mediana proximidade genética (bootstrap $=37 \%$ ), indicando, possivelmente, que as sementes tiveram uma fonte original comum. Estudos anteriores, desenvolvidos por Alves et al.(2007), indicaram que a variabilidade genética dentro é maior que entre as propriedades do município de Tomé-Açu. Estes autores analisaram a divergência genética entre as matrizes procedentes de 13 plantios comerciais de cupuaçuzeiro daquele município, concluindo que a seleção dentro de cada propriedade, devido à alta variabilidade, poderá resultar em ganhos genéticos promissores.

Outro cluster que merece atenção, constituído pelos acessos coletados na região Bragantina, no Estado do Pará (66 PA) e no município de Iranduba, no Amazonas (65 AM), apresentaram elevada afinidade (relationship), com valor significativo de bootstrap (71\%). Entretanto, como as áreas de coleta destes genótipos estão muito distantes (aproximadamente $1.600 \mathrm{~km}$; linha reta), a hipótese mais provável é que o material de Iranduba deva ter sido introduzido no Estado do Amazonas, proveniente de mudas ou sementes do Estado do Pará, um dos locais reconhecidos como centro de origem do cupuaçuzeiro (CUATRECASAS, 1964).

Em termos gerais, estes resultados indicam que este pequeno conjunto de acessos que exibem características agronômicas desejáveis, apresentam diversidade genética e podem ser explorados em programas de melhoramento de $T$. grandiflorum, através de cruzamentos controlados. Contudo, é importante que estes tenham seu pedigree controlado a fim de evitar-se cruzar acessos aparentados e gerar endogamia biparental.

Das 276 estimativas do coeficiente de coancestria entre pares de acessos, 23\% (64) apresentaram valores maiores que 0,1 (Tabela 5), sugerindo a existência de algum grau de parentesco entre os acessos. Contudo, a análise da herança destes genótipos indica que a possibilidade de eles serem parentes é nula, visto terem procedências diferentes e a distância espacial entre estas populações ser grande. Estimativas de parentescos por marcadores microssatélites assumem que alelos idênticos em estado entre indivíduos são idênticos por descendência e, por isso, são indivíduos aparentados, embora, isso nem sempre seja verdade, como no presente estudo. Entretanto, em 21 casos (7,6\%), a coancestria entre as plantas merece atenção e pode representar parentescos verdadeiros devido à identidade por descendência dos alelos, visto apresentarem a mesma procedência, como no caso dos acessos $95 \mathrm{AM}$ e $46 \mathrm{AM}$ que são irmãos completos $\left(\theta_{x y}=0,264\right)$ (Tabelas 1 e 5). Nestes 21 casos, a estimativa do coeficiente de coancestria variou entre os pares de indivíduos de 0,101 a 0,451 (média de 0,207), o que sugere que estes podem ser parentes entre meios-irmãos $\left(\theta_{x y}=0,125\right)$ a clones de plantas originadas de cruzamentos $\left(\theta_{x y}=0,500\right)$ (SEBBENN, 2006). Assim, como a coancestria entre indivíduos também representa a endogamia na descendência, o cruzamento entre estes 21 pares de acessos pode gerar endogamia equivalente à coancestria dos pais.

Alguns pares de acessos, apesar de não apresentarem parentesco direto evidente, foram coletados em localidades próximas, com provável fluxo gênico e/ou sementes/mudas. Esse é o caso dos clones 65 AM e $67 \mathrm{AM}$, coletados nas localidades de Iranduba e Manaus, que se situam em margens opostas do Rio Negro e apresentaram elevada coancestria $\left(\theta_{x y}=0,401\right)$; acessos 85 PA e $66 \mathrm{PA}\left(\theta_{x y}=0,140\right)$, ambos pertencentes à região Bragantina no nordeste paraense; e os acessos 95 AM (cruzamento 215 Manacapuru x 185 Codajás, 
ambos do Amazonas) e 174 AM (Coari, Amazonas), coancestria de 0,181 , cuja distância entre Coari e Codajás é de aproximadamente $130 \mathrm{~km}$ rio abaixo. Nestes casos, deve-se ter prudência na utilização conjunta destes pares de acessos em programa de melhoramento da espécie.

O par de acessos 77 RO (Guajará-Mirim) e 80 RO (Machadinho) apresentaram o maior coeficiente de coancestria $\left(\theta_{x y}=0,451\right)$, porém, possivelmente, seus alelos são idênticos por estado, não apresentando grau de parentesco verdadeiro, devido seus locais de coleta distarem cerca de $460 \mathrm{~km}$. Entretanto, os locais de origem destes acessos são interligados diretamente por estradas federal e estadual (BR421 e RO-257, respectivamente), e o transporte de sementes ou mudas entre as localidades é igualmente provável. Portanto, deve-se ter cautela, ou até mesmo evitar usá-los conjuntamente em hibridação, pois apresentam coeficiente de coancestria próximo ao de cruzamentos entre clones $(0,500)$, podendo gerar endogamia severa em sua progênie.

Assumindo que o parentesco entre estes 21 pares de genótipos é verdadeiro, e baseado no valor médio de coancestria $(\Theta=0,0199)$ e endogamia $(F=0,003)$, os 24 acessos de $T$. grandiflorum analisados representam um tamanho efetivo de 12 plantas não parentes e não endogâmicas.

TABELA 1- Código do acesso, Unidade de introdução e local de coleta de 24 acessos de Theobroma grandiflorum analisados.

\begin{tabular}{|c|c|c|}
\hline Código do acesso & Unidade de Introdução* & Local de coleta da Matriz \\
\hline 42 AM-PA & CPATU & 186 Codajás (AM) x 434 Muaná (PA) \\
\hline $46 \mathrm{AM}$ & CPATU & 186 Codajás $(\mathrm{AM}) \times 215$ Manacapuru (AM) \\
\hline $47 \mathrm{AM}$ & CPATU & 186 Codajás (AM) x 1074 Itacoatiara (AM) \\
\hline $65 \mathrm{AM}$ & CPAA & Iranduba (AM) \\
\hline $66 \mathrm{PA}$ & CPAA & Bragantina (PA) \\
\hline $67 \mathrm{AM}$ & CPAA & Manaus (AM) \\
\hline $68 \mathrm{PA}$ & CPAA & Bragantina (PA) \\
\hline $69 \mathrm{PA}$ & CPAA & Bragantina (PA) \\
\hline $70 \mathrm{PA}$ & CPAA & Bragantina (PA) \\
\hline $77 \mathrm{RO}$ & CPAFRO & Guajará-Mirim (RO) \\
\hline $78 \mathrm{RO}$ & CPAFRO & Cacoal (RO) \\
\hline $79 \mathrm{RO}$ & CPAFRO & Machadinho (RO) \\
\hline $80 \mathrm{RO}$ & CPAFRO & Machadinho (RO) \\
\hline $81 \mathrm{AM}$ & CPAFRO & Humaitá (AM) \\
\hline $82 \mathrm{RO}$ & CPAFRO & Porto Velho (RO) \\
\hline $84 \mathrm{AM}$ & CPATU & MI 218 Caapiranga $(\mathrm{AM})^{* *}$ \\
\hline $85 \mathrm{PA}$ & CPATU & MI 142 Tomé-Açu (PA) \\
\hline $88 \mathrm{PA}$ & CPATU & MI 274 Tomé-Açu (PA) \\
\hline $93 \mathrm{AM}$ & CPATU & MI 186 Codajás (AM) \\
\hline $94 \mathrm{AM}$ & CPATU & 186 Codajás (AM) x 248 Itacoatiara (AM) \\
\hline $95 \mathrm{AM}$ & CPATU & 215 Manacapuru (AM) x 185 Codajás (AM) \\
\hline $174 \mathrm{AM}$ & CPATU & Coari (AM) \\
\hline $186 \mathrm{AM}$ & CPATU & Codajás (AM) \\
\hline $215 \mathrm{AM}$ & CPATU & Manacapuru (AM) \\
\hline
\end{tabular}

*CPATU (Centro de Pesquisa Agropecuária dos Trópicos Úmidos); CPAFRO (Centro de Pesquisa Agroflorestal de Rondônia); CPAA (Centro de Pesquisa Agroflorestal da Amazônia Ocidental); ** MI - clone formado a partir de progênie de meio-irmão. 
TABELA 2- Loco microssatélite, localização no grupo de ligação de cacaueiro, tamanho do alelo clonado (Theobroma cacao), e estimados (Theobroma grandiflorum), em pares de base (pb), e número de alelos identificados na análise de 24 acessos de cupuaçuzeiro, utilizando 14 lócus microssatélites.

\begin{tabular}{ccccc}
\hline Loco & LG $^{*}$ & Alelo Clonado $(\mathrm{pb})^{* *}$ & Alelos Estimados $(\mathrm{pb})$ & $\mathrm{N}^{\circ}$. Alelos \\
\hline mTcCIR 17 & IV & 271 & 265,270 e 280 & 3 \\
mTcCIR 25 & VI & 153 & $133,135,137,145,155,160$ e 170 & 7 \\
mTcCIR 26 & VIII & 298 & $245,250,255,260$ e 270 & 5 \\
mTcCIR 32 & IV & 193 & 190 e 195 & 2 \\
mTcCIR 33 & IV & 285 & 220,240 e 250 & 3 \\
mTcCIR 54 & I & 165 & 145 & 1 \\
mTcCIR 57 & IV & 253 & 250,255 e 260 & 3 \\
mTcCIR 58 & IX & 266 & 210 e 220 & 2 \\
mTcCIR 75 & VIII & 121 & $112,114,115$ e 118 & 4 \\
mTcCIR 124 & IX & 131 & 155,160 e180 & 3 \\
mTcCIR 134 & VIII & 176 & 220,225 e 240 & 3 \\
mTcCIR 135 & III & 246 & $255,260,270$ e 300 & 4 \\
mTcCIR 264 & I & 192 & 185 e 188 & 2 \\
mTcCIR 276 & VI & 124 & 120,122 e 125 & 3 \\
\hline
\end{tabular}

* Lócus nos grupos de ligação do mapa consensual de Theobroma cacao (PUGH et al., 2004);

** Alelos clonados em Theobroma cacao (LANAUD et al., 1999).

TABELA 3- Estimativas de parâmetros genéticos e probabilidades de identidade e exclusão em 14 lócus microssatélites de Theobroma grandiflorum, em que Aé o número total de alelos; Ae: número médio efetivo de alelos/lócus; Ho: heterozigosidade observada; He: heterozigosidade esperada sob equilíbrio de Hardy-Weinberg; F: índice de fixação; PIC: conteúdo de informação polimórfica; PI : probabilidade de identidade; PE: probabilidade de exclusão, utilizando 24 acessos distribuídos em quatro populações.

\begin{tabular}{l|c|c|c|c|c|c|c|c}
\hline \multicolumn{1}{c}{ Loco } & \multicolumn{1}{c}{$A$} & \multicolumn{1}{c}{$H$ Ho } & \multicolumn{1}{c}{$H e$} & \multicolumn{1}{c}{ PIC } & \multicolumn{1}{c}{$P I$} & PE \\
\hline mTcCIR 17 & 3 & 2,98 & 0,522 & 0,679 & 0,236 & 0.590 & 0,186632 & 0,368683 \\
mTcCIR 25 & 7 & 3,99 & 0,667 & 0,765 & 0,131 & 0.712 & 0,100298 & 0,533937 \\
mTcCIR 26 & 5 & 2,21 & 0,458 & 0,559 & 0,185 & 0.556 & 0,201780 & 0,374909 \\
mTcCIR 32 & 2 & 2,00 & 1,000 & 0,511 & $-1,000$ & 0.375 & 0,375000 & 0,187500 \\
mTcCIR 33 & 3 & 1,94 & 0,417 & 0,494 & 0,159 & 0.385 & 0,365208 & 0,203022 \\
mTcCIR 54 & 1 & 1,00 & 0,000 & 0,000 & - & 0.000 & - & - \\
mTcCIR 57 & 3 & 2.36 & 0,333 & 0,589 & 0,440 & 0.528 & 0,233589 & 0,318787 \\
mTcCIR 58 & 2 & 1.92 & 0,458 & 0,488 & 0,063 & 0.368 & 0,382234 & 0,183980 \\
mTcCIR 75 & 4 & 2.41 & 0,500 & 0,598 & 0,167 & 0.498 & 0,258166 & 0,298851 \\
mTcCIR 124 & 3 & 2.28 & 0,500 & 0,574 & 0,131 & 0.529 & 0,231329 & 0,326337 \\
mTcCIR 134 & 3 & 2.97 & 0,792 & 0,677 & $-0,173$ & 0.359 & 0,392090 & 0,179443 \\
mTcCIR 135 & 4 & 2.45 & 0,542 & 0,604 & 0,105 & 0.601 & 0,169230 & 0,412112 \\
mTcCIR 264 & 2 & 2.00 & 1,000 & 0,511 & $-1,000$ & 0.218 & 0,594836 & 0,109049 \\
mTcCIR 276 & 3 & 2.11 & 0,375 & 0,536 & 0,305 & 0.424 & 0,326254 & 0,232713 \\
\hline \multicolumn{1}{c}{ Média } & 3,21 & 2,33 & 0,540 & 0,542 & 0,003 & 0.439 & - & - \\
\hline Desvio-Padrão & 1,48 & 0,68 & 0,263 & 0,175 & - & - & & - \\
Total de Alelos & 45 & & & & & & & \\
\hline
\end{tabular}


TABELA 4 -Alelos exclusivos de acessos de Theobroma grandiflorum estabelecidos no Banco Ativo de Germoplasma da EMBRAPA, utilizando lócus microssatélites.

\begin{tabular}{lccc}
\hline & \multicolumn{3}{c}{ Alelos exclusivos } \\
\hline \multicolumn{1}{c}{ Lócus } & Alelo & Frequência & Acesso \\
\hline mTcCIR 25 & 155 & 1 & $79 \mathrm{RO}$ \\
mTcCIR 33 & 220 & 0,5 & $78 \mathrm{RO}$ \\
mTcCIR 75 & 118 & 0,5 & $174 \mathrm{AM}$ \\
mTcCIR 276 & 125 & 1 & $65 \mathrm{AM}$ \\
\hline
\end{tabular}

TABELA 5- Estimativa do coeficiente de coancestria entre pares de acessos de Theobroma grandiflorum que apresentaram valores $\geq 0,1$.

\begin{tabular}{ccccccccc}
\hline Ind_1 & Ind_2 & $\theta_{x y}$ & Ind_1 & Ind_2 & $\theta_{x y}$ & Ind_1 & Ind_2 & $\theta_{x y}$ \\
\hline $174 \mathrm{AM}$ & $215 \mathrm{AM}$ & 0,108 & $78 \mathrm{RO}$ & $68 \mathrm{PA}$ & 0,164 & $85 \mathrm{PA}$ & $88 \mathrm{PA}$ & 0,252 \\
$174 \mathrm{AM}$ & $69 \mathrm{PA}$ & 0,311 & $78 \mathrm{RO}$ & $79 \mathrm{RO}$ & 0,179 & $85 \mathrm{PA}$ & $47 \mathrm{AM}$ & 0,116 \\
$174 \mathrm{AM}$ & $70 \mathrm{PA}$ & 0,148 & $78 \mathrm{RO}$ & $81 \mathrm{AM}$ & 0,218 & $88 \mathrm{PA}$ & $46 \mathrm{AM}$ & 0,240 \\
$174 \mathrm{AM}$ & $77 \mathrm{RO}$ & 0,385 & $79 \mathrm{RO}$ & $68 \mathrm{PA}$ & 0,212 & $88 \mathrm{PA}$ & $93 \mathrm{AM}$ & 0,146 \\
$215 \mathrm{AM}$ & $82 \mathrm{RO}$ & 0,155 & $79 \mathrm{RO}$ & $70 \mathrm{PA}$ & 0,162 & $88 \mathrm{PA}$ & $94 \mathrm{AM}$ & 0,152 \\
$42 \mathrm{AM}-\mathrm{PA}$ & $66 \mathrm{PA}$ & 0,158 & $79 \mathrm{RO}$ & $82 \mathrm{RO}$ & 0,176 & $88 \mathrm{PA}$ & $95 \mathrm{AM}$ & 0,167 \\
$42 \mathrm{AM}-\mathrm{PA}$ & $80 \mathrm{RO}$ & 0,138 & $80 \mathrm{RO}$ & $66 \mathrm{PA}$ & 0,111 & $93 \mathrm{AM}$ & $42 \mathrm{AM}-\mathrm{PA}$ & 0,131 \\
$46 \mathrm{AM}$ & $174 \mathrm{AM}$ & 0,184 & $80 \mathrm{RO}$ & $69 \mathrm{PA}$ & 0,306 & $93 \mathrm{AM}$ & $46 \mathrm{AM}$ & 0,101 \\
$46 \mathrm{AM}$ & $186 \mathrm{AM}$ & 0,140 & $80 \mathrm{RO}$ & $81 \mathrm{AM}$ & 0,162 & $93 \mathrm{AM}$ & $69 \mathrm{PA}$ & 0,158 \\
$46 \mathrm{AM}$ & $215 \mathrm{AM}$ & 0,119 & $81 \mathrm{AM}$ & $66 \mathrm{PA}$ & 0,182 & $93 \mathrm{AM}$ & $94 \mathrm{AM}$ & 0,226 \\
$46 \mathrm{AM}$ & $77 \mathrm{RO}$ & 0,113 & $81 \mathrm{AM}$ & $67 \mathrm{AM}$ & 0,286 & $94 \mathrm{AM}$ & $186 \mathrm{AM}$ & 0,122 \\
$46 \mathrm{AM}$ & $47 \mathrm{AM}$ & 0,246 & $81 \mathrm{AM}$ & $68 \mathrm{PA}$ & 0,392 & $94 \mathrm{AM}$ & $42 \mathrm{AM}-\mathrm{PA}$ & 0,137 \\
$* 65 \mathrm{AM}$ & $67 \mathrm{AM}$ & 0,401 & $82 \mathrm{RO}$ & $66 \mathrm{PA}$ & 0,164 & $94 \mathrm{AM}$ & $46 \mathrm{AM}$ & 0,107 \\
$65 \mathrm{AM}$ & $70 \mathrm{PA}$ & 0,268 & $82 \mathrm{RO}$ & $67 \mathrm{AM}$ & 0,126 & $94 \mathrm{AM}$ & $69 \mathrm{PA}$ & 0,164 \\
$66 \mathrm{PA}$ & $65 \mathrm{AM}$ & 0,297 & $82 \mathrm{RO}$ & $69 \mathrm{PA}$ & 0,146 & $* 95 \mathrm{AM}$ & $174 \mathrm{AM}$ & 0,181 \\
$66 \mathrm{PA}$ & $67 \mathrm{AM}$ & 0,306 & $84 \mathrm{AM}$ & $215 \mathrm{AM}$ & 0,351 & $95 \mathrm{AM}$ & $215 \mathrm{AM}$ & 0,259 \\
$67 \mathrm{AM}$ & $70 \mathrm{PA}$ & 0,275 & $84 \mathrm{AM}$ & $65 \mathrm{AM}$ & 0,241 & $95 \mathrm{AM}$ & $46 \mathrm{AM}$ & 0,264 \\
$68 \mathrm{PA}$ & $65 \mathrm{AM}$ & 0,153 & $84 \mathrm{AM}$ & $88 \mathrm{PA}$ & 0,117 & $95 \mathrm{AM}$ & $47 \mathrm{AM}$ & 0,101 \\
$68 \mathrm{PA}$ & $67 \mathrm{AM}$ & 0,304 & $85 \mathrm{PA}$ & $42 \mathrm{AM}-\mathrm{PA}$ & 0,237 & $47 \mathrm{AM}$ & $186 \mathrm{AM}$ & 0,190 \\
$68 \mathrm{PA}$ & $70 \mathrm{PA}$ & 0,315 & $85 \mathrm{PA}$ & $46 \mathrm{AM}$ & 0,208 & $47 \mathrm{AM}$ & $70 \mathrm{PA}$ & 0,137 \\
$77 \mathrm{RO}$ & $69 \mathrm{PA}$ & 0,312 & $* 85 \mathrm{PA}$ & $66 \mathrm{PA}$ & 0,140 & & & \\
$77 \mathrm{RO}$ & $80 \mathrm{RO}$ & 0,451 & $85 \mathrm{PA}$ & $81 \mathrm{AM}$ & 0,120 & & & \\
\hline
\end{tabular}

* Acessos com locais de coleta próximos, com provável fluxo gênico. 


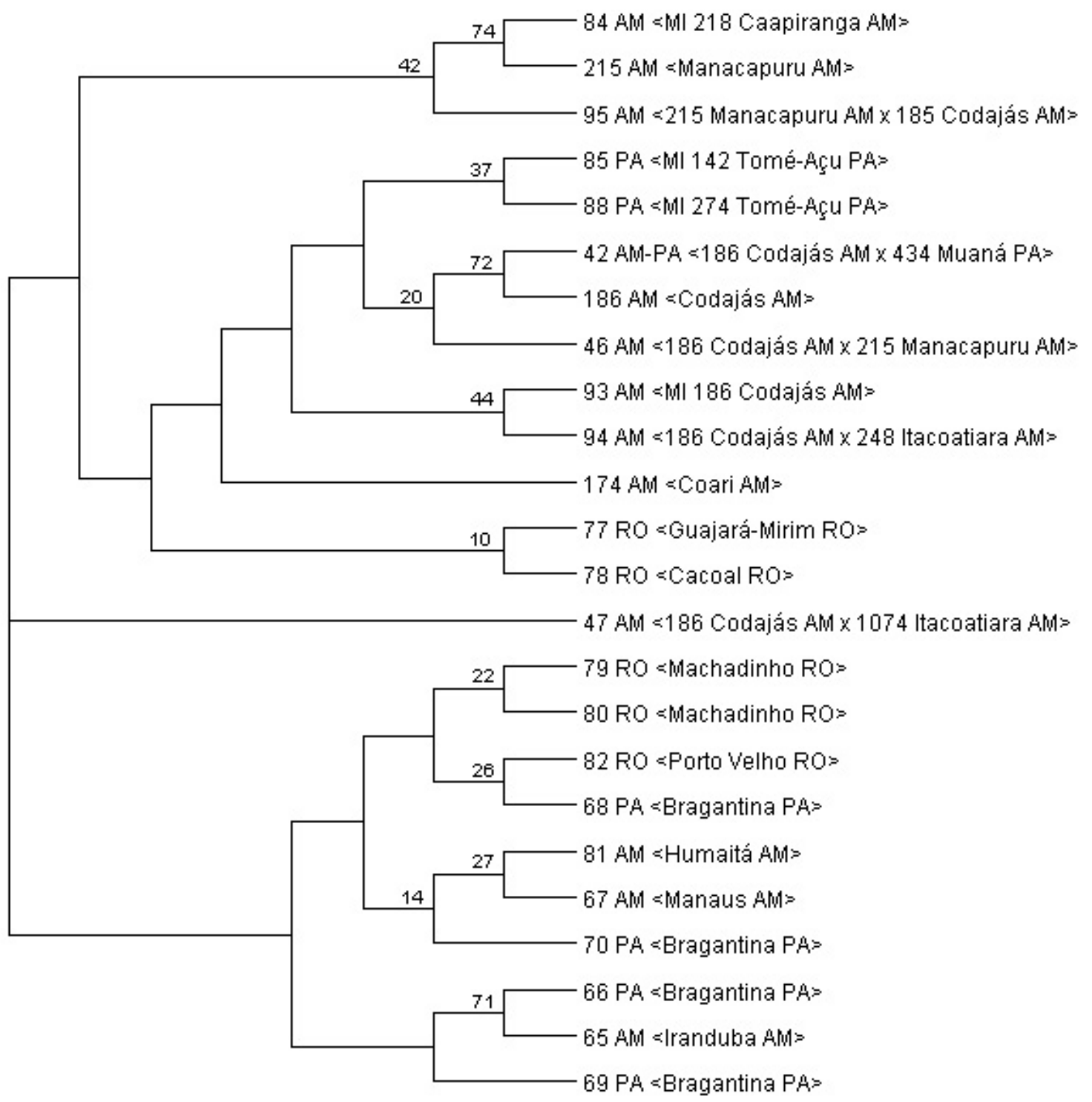

FIGURA 1- Dendrograma baseado na distância genética $D_{A}$ (NEI et al., 1983) entre 24 acessos de Theobroma grandiflorum estabelecidos em diferentes coleções de germoplasma de cupuaçuzeiro da Amazônia brasileira, agrupados, utilizando o método de médias das distâncias (UPGMA). Os números nos clusters representam os $P$ valores de bootstrap $\geq 0,100$, referentes a 10.000 replicações. 


\section{CONCLUSÃO}

1-Os acessos de Teobroma grandiflorum em estudo apresentam diversidade genética com moderado nível de riqueza alélica, provavelmente, devido ao número de genótipos analisados e por se tratarem de lócus heterólogos. Porém, apresentam potencial a ser explorado em programas de melhoramento genético da espécie.

2-Os acessos não exibem endogamia.

3-Muitos dos acessos são parentes entre si, consequentemente, deve-se considerar o fingerprint dos materiais a fim de evitar promover depressão endogâmica nas futuras progênies, o que pode reduzir a produtividade de frutos.

\section{REFERÊNCIAS}

ALVERSON W.S.; WHITLOCK B.A.; NYFFLER R.; BAYER C.; BAUM D.A. Phylogeny of the core Malvales: evidence from $\mathrm{ndhF}$ sequence data. American Journal of Botany, St. Louis, v.86, p.1474-1486, 1999.

ALVES, R. M.; ARTERO, A. S.; SEBBENN, A. M.; CLEMENT, C.; FIGUEIRA, A. High levels of genetic divergence and inbreeding in populations of cupuassu, Theobroma grandiflorum. Tree Genetics \& Genomes, St. Louis,v.3, p.289-298, 2007.

COCKERHAM, C.C. Variance of gene frequencies. Evolution, Washington, v.23, p.72-84, 1969.

CRESTE, S.; TULMANN-NETO, A.; FIGUEIRA, A. Detection of single sequence repeat polymorphisms in denaturing polyacrylamide sequencing gels by silver staining. Plant Molecular Biology Reporter, New York, v.19, p.299-306, 2001.

CUATRECASAS, J. A. Cocoa and its aliies: a taxonomic revision of the genus Theobroma. Contributions from the United States National Herbarium, Washington, v.35, n.6, p.32-46, 1964.

DOYLE, J.J.; DOYLE, J.L. Isolation of plant DNA from fresh tissue. Focus, Oxford,v.12, n.1, p.1315, 1990.

FELSENSTEIN, J. Confidence limits on phylogenies: an approach using the bootstrap. Evolution, Washington, v.39, p.783-791, 1985.
GOUDET, J. Fstat. (Version 2.9.3.2.): a computer program to calculate $F$-statistics. Journal of Heredity, Edinburg, v.86, p.485-486. 1995.

HARDY, O.; VEKEMANS, X. SPAGeDI: a versatile computer program to analyze spatial genetic structure at the individual or population levels. Molecular Ecology Notes, Lawrence v.2, p. 618-620, 2002.

IRISH, B.M.; GOENAGA, R.; ZHANG, D.; SCHNELL, R.; BROWN, J.S.; MOTAMAYOR, J. C. Microsatellite Fingerprinting of the USDAARS Tropical Agriculture Research Station Cacao (Theobroma cacao L.) Germplasm Collection. Crop Science, Madison,v. 50, p.656-667, 2010.

LANAUD, C.; RISTERUCCI, A.M.; PIERETTI, I.; FALQUE, M.; BOUET, A.; LAGODA, P.J.L. Isolation and characterization of microsattelites in Theobroma cacao L. Molecular Ecology, Lawrence,v.8, p.2141-2143, 1999.

LEMES, M.R.; MARTINIANO, T.M.; REIS, V.M.; FARIA, C.P.; GRIBEL, R. Cross-amplification and characterization of microsatellite loci for three species of Theobroma (Sterculiaceae) from the Brazilian Amazon. Genetic Resources and Crop Evolution, New York, v. 54, p.1653-1657, 2007.

LOISELLE, B.A.; SORK, V.L.; NASON, J.; GRAHAM, D.C. Spatial genetic structure of a tropical understory shrub, Psychotria officinalis (Rubiaceae). American Journal of Botany. St. Louis, v.82, p.1420-1425, 1995.

NEI, M.; TAJIMA, F.; TATENO, Y. Accuracy of estimated phylogenetic trees from molecular data. Journal of Molecular Evolution, New York, , v.19, p. 153-170, 1983.

PAETKAU, D.; CALVERT, W.; STIRLING, I.; STROBECK, C. Microsatellite analysis of population structure in Canadian polar bears. Molecular Ecology, Lawrence, v.4, p. 347-354. 1995.

PUGH, T.; FOUET, O.; RISTERUCCI, A.M.; BROTTIER, P.; ABOULADZE, M.; DELETREZ, C.; COURTOIS, B.; CLEMENT, D.; LARMANDE, P.; N`GORAN, J.A.K.; LANAUD, C. A new cacao linkage map based on codominant markes: development and integration of 201 new microsatellite markes. Theoretical and Applied Genetics, New York, v.108, n.5, p.1151-1161, 2004. 
RISTERUCCI, A. M.; GRIVET, L.; N'GORAN, J. A. K.; PIERETTI, I.; FLAMENT, M. H.; LANAUD, C. A high-density linkage map of Theobroma cacao L. Theoretical and Applied Genetics, New York, v.101, p.948-55, 2000

SCHNELL, R.J.; KUHN, D.N.; BROWN, J.S.; OLANO, C.T.; PHILLIPS-MORA, W.; AMORES, F.M.; MOTAMAYOR, J.C. Development of a Marker Assisted Selection Program for Cacao. Phytopathology, St. Paul, v.97, n.12, p.1664-1669, 2007.

SEBBENN, A.M. Sistema de reprodução em espécies arbóreas tropicais e suas implicações para a seleção de árvores matrizes para reflorestamentos ambientais. In: HIGA, A.R.; SILVA, L. Pomares de sementes de espécies nativas. Curitiba: FUPEF, 2006. p.193-198.

SERENO, M.L.; ALBUQUERQUE, P.S.B.; VENCOVSKY, R.; FIGUEIRA, A. Genetic diversity and natural population structure of cacao (Theobroma cacao L.) from the Brazilian Amazon evaluated by microsatellite markers. Conservation Genetics, New York, v.7, n.1, p.13-24, 2006.

SILVA, C.R.S.; ALBUQUERQUE, P.S.B.; ERVEDOSA, F.R.; MOTA, J.W.S; FIGUEIRA, A; SEBBENN, A.M. Understanding the genetic diversity, spatial genetic structure and mating system at the hierarchical levels of fruits and individuals of a continuous Theobroma cacao population from the Brazilian Amazon. Heredity, Essex, p.973-985, 2011.
SILVA, C.R.S; VENTURIERI, G. A.; FIGUEIRA, A.. Description of Amazonian Theobroma L. collections, species identification, and characterization of interspecific hybrids. Acta Botanica Brasílica, Feira de Santana,v.18, p.333-340, 2004.

SOUZA, A. G. C.; RESENDE, M. D. V.; SILVA, S. E. L.; SOUZA, N. R. . The cupuaçuzeiro genetic improvement program at Embrapa Amazônia Ocidental. Crop Breeding And Applied Biotechnology, Londrina, v.2, n.3, p.471-478, 2002.

TAKEZAKI, N.; NEI, M.; TAMURA, K. POPTREE2: Software for Constructing Population Trees from Allele Frequency Data and Computing Other Population Statistics with Windows Interface. Molecular Biology and Evolution, Lawrence, v.27, n.4, p.747-752, 2010.

WAGNER, H.W.; SEFC, K.M., Identity 1.0. Vienna: Centre for Applied Genetics, University of Agricultural Sciences Vienna, 1999. p.458. 